\title{
PROGRAMA BRASIL QUILOMBOLA: UM ENSAIO SOBRE A POLÍTICA PÚBLICA DE PROMOÇÃO DA IGUALDADE RACIAL PARA COMUNIDADES DE QUILOMBOS*
}

\section{RESUMO}

A política pública no Brasil possui um novo marco a partir da Constituição Federal de 1988, a qual inovou no reconhecimento de direitos etnorraciais e territoriais. Por conta disso, emergiram das lutas sociais novos sujeitos de direitos e cidadania: as comunidades de quilombos. Desse contexto surge a política pública de promoção da igualdade racial direcionada à população negra. Nesse ensaio, analisa-se um modelo dessa política, o Programa Brasil Quilombola, que, dentre os seus eixos de atuação, objetiva o reconhecimento e titulação territorial das comunidades quilombolas. Tal recorte justifica-se na centralidade que as comunidades quilombolas, como sujeitos da política pública, têm evidenciado na dinâmica conceitual e política da problemática fundiária e racial do país.

PALAVRAS-CHAVE Equidade, movimentos negros, política pública, quilombos, relações raciais.

Vera Rodrigues verarodrigues@usp.br

Doutoranda no Programa de Pós Graduação em Antropologia Social da Universidade de São Paulo e Bolsista do Programa de Bolsas de PósGraduação da Fundação Ford.

Artigo submetido no dia 08/09/2010 e aprovado no dia 23/11/2010.

ABSTRACT The public policy in Brazil has a new landmark from the 1988 Federal Constitution, which broke new ground in recognizing ethnic, racial and territorial rights. Because of this, new social subjects of rights and citizenship have emerged of the social struggles: the Quilombo communities. In this context arises the public policy of promoting racial equality targeted the black population. In this essay, we analyze a model that policy, the Quilombola Brazil Program, which, among its axis of action, aims the recognition and land regularization of quilombolas communities. Such delimitation is justified on the centrality that the quilombolas communities, as subjects of public policy, have demonstrated in the conceptual and political dynamics of land and racial issues in the country.

KEYWORDS Equity, black movements, quilombos, public policy, racial relations.

* Este artigo recebeu Menção Honrosa na categoria doutorando/doutor na $2^{a}$ edição do Concurso de Ensaios e Monografias sobre Experiências Inovadoras no Campo das Políticas Públicas com Foco na Redução das Desigualdades, o prêmio Políticas Públicas e Equidade: Avanços Práticos. 


\section{INTRODUÇÃO}

O presente ensaio emerge na contemporaneidade dos debates político-científicos, relativos às políticas públicas de promoção da igualdade racial direcionadas à população negra brasileira. ${ }^{1}$ Nesse contexto, tão marcado pela pluralidade de entendimentos acerca da própria política, bem como das representações das ideias envolvidas, tais como "raça" e a realidade concreta que esta enseja, debatem militantes dos movimentos negros, intelectuais, juristas, formuladores e gestores de políticas públicas. O processo desses debates origina uma arena pública de disputa conceitual e política que abarca não só a noção sobre "raça", mas também "igualdade", e/ou "equidade" como pontos conflitivos e complexos. Por consequência, nessa arena também se destacam as diversas áreas sociais enfocadas (saúde, educação, trabalho), público-alvo (mulheres, crianças e adolescentes, estudantes universitários, quilombos) e mecanismos de implementação (cotas, bônus, titulação territorial).

A minha proposta neste ensaio é fazer um recorte nesse processo, e analisar o "desenho" da política pública direcionada para as comunidades de quilombos no tocante ao processo de reconhecimento e titulação dos seus territórios. Por desenho, compreendo a proposta de Souza (2006) em buscar analisar o problema, conflitos, trajetória de indivíduos, grupos e instituições envolvidos e afetados pela política pública. Tal recorte justifica-se na centralidade que as comunidades quilombolas, como sujeitos de políticas públicas, têm evidenciado na dinâmica conceitual e política da problemática racial no país. Um exemplo disso é que, além da noção de "raça", também desde o século XIX se constroem noções sobre quilombos, tais como: grupos de escravos fugidos; expressões de resistência cultural e política; grupos sociais étnica e culturalmente diferenciados; processos identitários coletivos e mais recen- temente novos sujeitos de direitos socioculturais.

Outra justificativa vem do campo de análises sobre políticas públicas, pois atento para a emergente demanda por análises sistemáticas dos impactos e eficácias das ações da administração pública sobre determinados segmentos sociais, e/ou um balanço da conversão da regularização fundiária quilombola em objeto de política pública, conforme já apontam Arruti (2008), Jaccoud (2008) e Lima (2008). Nesse fértil campo teórico, me proponho, ainda que via passos iniciais, percorrer algumas das contribuições advindas de campos diversos do conhecimento e da ação social, que (re)elaboram visões e tecem discursos pertinentes para os propósitos de contribuir para os estudos sobre políticas públicas e equidade.

Para melhor situar essa proposta, começo o ensaio com a contextualização da política pública no Brasil desde uma percepção mais universalista até chegar à atualidade com as políticas públicas de promoção da igualdade racial. Nesse processo evidencio os atores sociais envolvidos e o cenário político nacional.

Finalizarei com uma leitura do estado da arte do Programa Brasil Quilombola desde sua criação, em 2004, até 2009, com a exposição de dados de implementação da política no contexto nacional. Como exemplo de caso, trago dados relativos ao estado de São Paulo.

\section{DA POLÍTICA PÚBLICA UNIVERSAL À POLÍTICA PÚBLICA PELA IGUALDADE RACIAL NO BRASIL}

As políticas públicas no Brasil possuem um histórico complexo que abrange desde sua elaboração teórica até sua aplicação prática. Para começar, na literatura especializada encontram-se múltiplas definições resultantes do acúmulo teórico sobre 
o tema. Em Silva; Melo (2000) e Souza (2006) há definições clássicas concentradas na análise do Estado, instituições e ação governamental. Tais definições vêm ancoradas, principalmente, na tradição dos estudos oriundos do campo da ciência política, sociologia e administração pública, onde também foram cunhadas as expressões policy analysis (análise da política pública); policy makers (tomadores de decisão); policy cicle (ciclo de política); impact analysis or evaluation (impacto ou avaliação da política) pelos "pais fundadores" H. Laswell, H. Simon, C. Lindblom e D. Easton.

A definição que utilizarei segue a síntese de política pública que Souza (2006) faz em termos daquilo que "o governo escolhe fazer ou não fazer" e que implica buscar responder quem ganha o quê com a política pública, por que e que diferença isso faz no cenário social. Essa é uma proposta, a meu ver, em diálogo com dois modelos explicativos do processo de formulação de políticas públicas: o modelo de "arenas sociais" e de "múltiplos fluxos".

O modelo de arenas sociais vê a política pública como uma iniciativa dos chamados empreendedores políticos ou de políticas públicas. Isto porque, para que uma determinada circunstância ou evento se transforme em um problema, é preciso que as pessoas se convençam de que algo precisa ser feito. $\dot{E}$ quando os policy makers do governo passam a prestar atenção em algumas questões e ignorar outras. (...) Esses empreendedores constituem redes sociais que envolvem contatos, vínculos e conexões que relacionam os agentes entre si. [...] O foco está no conjunto de relações, vínculos e trocas entre entidades e indivíduos (SOUZA, 2006 p. 32).

[...] Kingdon considera as políticas públicas como um conjunto formado por quatro processos: o estabelecimento de uma agenda de políticas públicas; a consideração das alternativas para a formulação de políticas públicas, com base nas quais escolhas serão realizadas; a escolha dominante entre $\mathrm{o}$ conjunto de alternativas disponíveis e, finalmente, a implementação da decisão. Em seu modelo de multiple streams, o autor preocupa-se especificamente com os dois primeiros processos, chamados estágios prédecisórios: a formação da agenda (agenda-setting) e as alternativas para a formulação das políticas (policy formulation) (CAPELLA, 2007 p. 88).

A reflexão, com base na complementaridade desses modelos, privilegia o olhar para a formulação de políticas públicas como ponto inicial que deflagra todo um processo que produzirá resultados concretos na realidade social. Assim, utilizo o modelo de "arenas sociais" para analisar como se dão as relações entre aqueles que demandam a política pública e aqueles que deverão implementá-la; e posso, de forma complementar, observar via modelo de "múltiplos fluxos" como e quais foram os mecanismos utilizados no jogo relacional capazes ou não de transpor a abstração de um problema para a concretude da solução; ou ainda a dinâmica de construção de uma agenda política.

Por essa via, chego ao momento atual em que Estado e sociedade convergem - ainda que de forma tensa, parcial e incipiente - para as políticas públicas de promoção da igualdade racial, bem como o período que o antecede. Se, temporalmente, for dividida a arena social da política pública no Brasil, o marco será a Constituição Federal de 1988, a Constituição Cidadã. Assim, tomo como ponto de ruptura o artigo $3^{\circ}$ relativo ao compromisso estatal com a redução das desigualdades sociais:

Art. 3 - Constituem objetivos fundamentais da República Federativa do Brasil: III - erradicar a pobreza e a marginalização e reduzir as desigualdades sociais e regionais; IV - promover o bem de todos, sem preconceitos de origem, raça, sexo, cor, idade e quaisquer outras formas de discriminação (CONSTITUIÇÃO DA REPÚBLICA FEDERATIVA DO Brasil, 1988).

O antes e o pós 1988 têm marcas próprias, as quais podem dizer algo sobre o caminho percorrido até aqui. Por exemplo, em Bacelar (2003), o período que abrange entre 1920 e 1980 caracteriza um Estado desenvolvimentista, conservador, 


\section{VERA RODRIGUES}

centralizador e autoritário, cujo objetivo maior era consolidar o processo de industrialização, portanto uma política de caráter notadamente econômico. Segundo a autora, o contraponto a essa política desenvolvimentista foi a desigualdade gerada pelo modelo político e econômico adotado. Outra interpretação desse dado indica que a política de cunho social ficou por conta do direcionamento às áreas de previdência, legislação trabalhista, saúde, educação, saneamento básico, habitação e transporte.

As áreas de saúde e saneamento refletiram certo conservadorismo, pois incidiram basicamente no controle de doenças e epidemias e não necessariamente na qualidade e oferta de serviços básicos à população. Tal postura pode ser relembrada via episódio da Revolta da Vacina (Rio de Janeiro, 1904), ocasião em que a população foi alvo tanto de uma política higienista, quanto de uma reforma urbana que previa a remoção de determinados grupos sociais (pobres, desempregados, mendigos) do centro da cidade para as periferias. Na área da educação também há críticas quanto ao investimento feito no acesso à educação básica e ao formato da política educacional. Nas demais áreas também coexistiram contradições entre avanços (direitos trabalhistas) e recuos (limitada participação política dos trabalhadores).

Nesse ínterim, fatores como o patrimonialismo e populismo engessaram de tal forma a estrutura social que dificultaram a organização da sociedade e a reivindicação por direitos. A influência desses fatores pode ser pensada, a partir da leitura de Silvério (2009, p. 15-17), em que se verifica que, da era Vargas, passando pelo plano de metas do governo Juscelino Kubitschek até o milagre econômico dos governos militares, o desenvolvimento econômico brasileiro se refletiu de forma desigual para o conjunto da população:

No Brasil, a sequência acima sugerida se inverteu [refere-se ás fases no desenvolvimento dos direitos do homem: direitos civis e políticos, em seguida os direitos sociais] os direitos sociais foram institucionalmente desenvolvidos a partir da década de trinta do século XX. No entanto, os direitos civis, mesmo figurando em todas as Constituições, foram constantemente desrespeitados. O peso da herança colonial, da escravidão e da grande propriedade privada são fatores que produziram um país comprometido com o poder privado e com uma ordem social que, ao negar a condição humana de grande parcela da população, obstruía e reprimia intencionalmente a participação popular (SILVÉRIO, 2009, p. 18).

Um aspecto agregador, ao que traz Silvério (2009) em relação à negação da condição humana da população negra, surge em Santos (2000) quando o autor estabelece um paralelo entre a noção teórica de cidadania e o seu exercício condicionado ao lugar social ocupado pelo indivíduo negro na sociedade brasileira:

[...] A cidadania define-se teoricamente por franquias políticas, de que se pode efetivamente dispor, acima e além da corporeidade e da individualidade, mas, na prática brasileira, ela se exerce em função da posição relativa de cada um na esfera social. Costuma-se dizer que uma diferença entre os Estados Unidos e o Brasil é que lá existe uma linha de cor e aqui não. Em si mesma, essa distinção é pouco mais do que alegórica, pois não podemos aqui inventar essa famosa linha de cor. Mas a verdade é que, no caso brasileiro, o corpo da pessoa também se impõe como uma marca visível e é frequente privilegiar a aparência como condição primeira de objetivação e de julgamento, criando uma linha demarcatória, que identifica e separa, a despeito das pretensões de individualidade e de cidadania do outro (SANTOS, 2000, p. 2).

A leitura de Santos (2000) pode ser provocativa, em termos de alguns questionamentos: Qual foi a cidadania que a população pode dispor na franquia política? Porque os empreendedores sociais, no caso os movimentos negros, ${ }^{2}$ só recentemente conseguem inserir na agenda política uma pauta propositiva de políticas públicas? Arriscando uma resposta: a causalidade dos processos que 
delimitam a cidadania e influenciam a formulação de políticas públicas, encontra no conceito de racismo institucional, uma explicação adicional para o tema das desigualdades:

A incapacidade coletiva de uma organização em prover um serviço apropriado ou profissional às pessoas devido à sua cor, cultura ou origem étnica. Ele pode ser visto ou detectado em processos, atitudes e comportamentos que contribuem para a discriminação através de preconceito não intencional, ignorância, desatenção e estereótipos racistas que prejudicam minorias étnicas. Em qualquer caso, o racismo institucional sempre coloca pessoas de grupos raciais ou étnicos em desvantagem no acesso a benefícios gerados pelo Estado e por demais instituições e organizações (ORGANIZAÇÃO..., 2006).

[...] a partir dos projetos politicos que assumiram em seus programas de governo o compromisso com esta bandeira fundamental do movimentos negros: o Estado tem a responsabilidade de atuar contra as desigualdades sociais e raciais no Brasil. São dezenas de novos gestores e gestoras que se deparam com uma máquina estatal ainda despreparada, em grande medida, para lidar com os desafios de inclusão social das populações negra e indígena, por exemplo, ao mesmo tempo em que enfrentam nas estruturas governamentais o chamado racismo institucional (RIBEIRO, 2009, p. 5).

A incapacidade e/ou o fracasso estatal na promoção da equidade, só muito recentemente, por volta dos anos noventa, teve no conceito de "racismo institucional" uma ferramenta de análise no campo das desigualdades sociorraciais. A incorporação conceitual suscitou uma travessia entre a análise que, geralmente, focava o racismo no nível das relações interpessoais para uma análise, e também a intervenção, no plano institucional. Isso acarretou envolver o Estado, suas instituições e todo o aparato que o sustenta numa leitura mais abrangente do cenário político brasileiro.

Em decorrência disso, entre os anos de 20012007 realizou-se o Programa de Combate ao Racismo Institucional (PCRI), que através de uma parceria entre poder público, organizações dos movimentos negros e agências internacionais buscou atuar favoravelmente na formulação e implementação de políticas públicas de promoção da igualdade racial. Ainda, que não estejam disponíveis os dados de avaliação do PCRI, é possível considerar interessante essa iniciativa no setor público pelo desafio que representa para a superação de desigualdades.

O desafio de superação das desigualdades sociorraciais tem destacado o papel dos movimentos negros na luta por cidadania. Se a noção de cidadania, como me provoca a pensar Dagnino (1994), comporta a dimensão de estratégia política, justamente por expressar interesses, desejos e aspirações de parte da sociedade, abrigando assim projetos diferenciados em seu interior, tem-se na experiência dos movimentos sociais nos anos 1990 uma experiência concreta dessa dimensão. No caso, os movimentos negros protagonizam uma luta por direitos que se dá tanto pela via do direito à igualdade, quanto à diferença; já que emergem da luta política especificidades em direitos e sujeitos, como ocorre com as comunidades quilombolas e as demandas por reconhecimento.

Se Santos (2000) fala de uma "cidadania mutilada" da população negra, Dagnino (1994) indica uma cidadania "de baixo para cima" via constituição de sujeitos sociais ativos que definem seus direitos e lutam por seu reconhecimento. Essa "cidadania de baixo para cima" transparece nas políticas públicas de promoção da igualdade racial desencadeadas, a partir do marco da Constituição Federal de 1988. Esse período é emblemático para os movimentos sociais de forma geral, os quais se fortalecem no cenário de redemocratização do país. Assim é que organizações representativas dos direitos das mulheres, homossexuais, juventude e negros, por exemplo, protagonizam demandas ao poder público com vistas à concretização da cidadania e da própria democracia.

No que tange aos movimentos negros, esse período demarca uma nova fase de sua atuação política, pois ultrapassa o viés da denúncia para 
investir na proposição de políticas públicas. Essa dinâmica em relação ao Estado tem sido marcada por avanços e recuos na resposta governamental, além do reflexo disso no seio dos próprios movimentos. Os principais fatos dessa dinâmica se dão ao longo dos mandatos presidenciais de três governos: José Sarney (1985-1990); Fernando Henrique Cardoso (1995-1999) e (1999-2003);
Luiz Inácio Lula da Silva (2003-2007) e (20072011). A seguir, estabeleço uma linha de tempo que abrange a dinâmica de demanda e ação governamental nesse período, entre os movimentos negros e o Estado brasileiro, na construção de uma agenda de políticas promotoras da igualdade racial.

Figura 1 - Linha de tempo: demandas dos movimentos negros e ação do Estado (1985-2011)

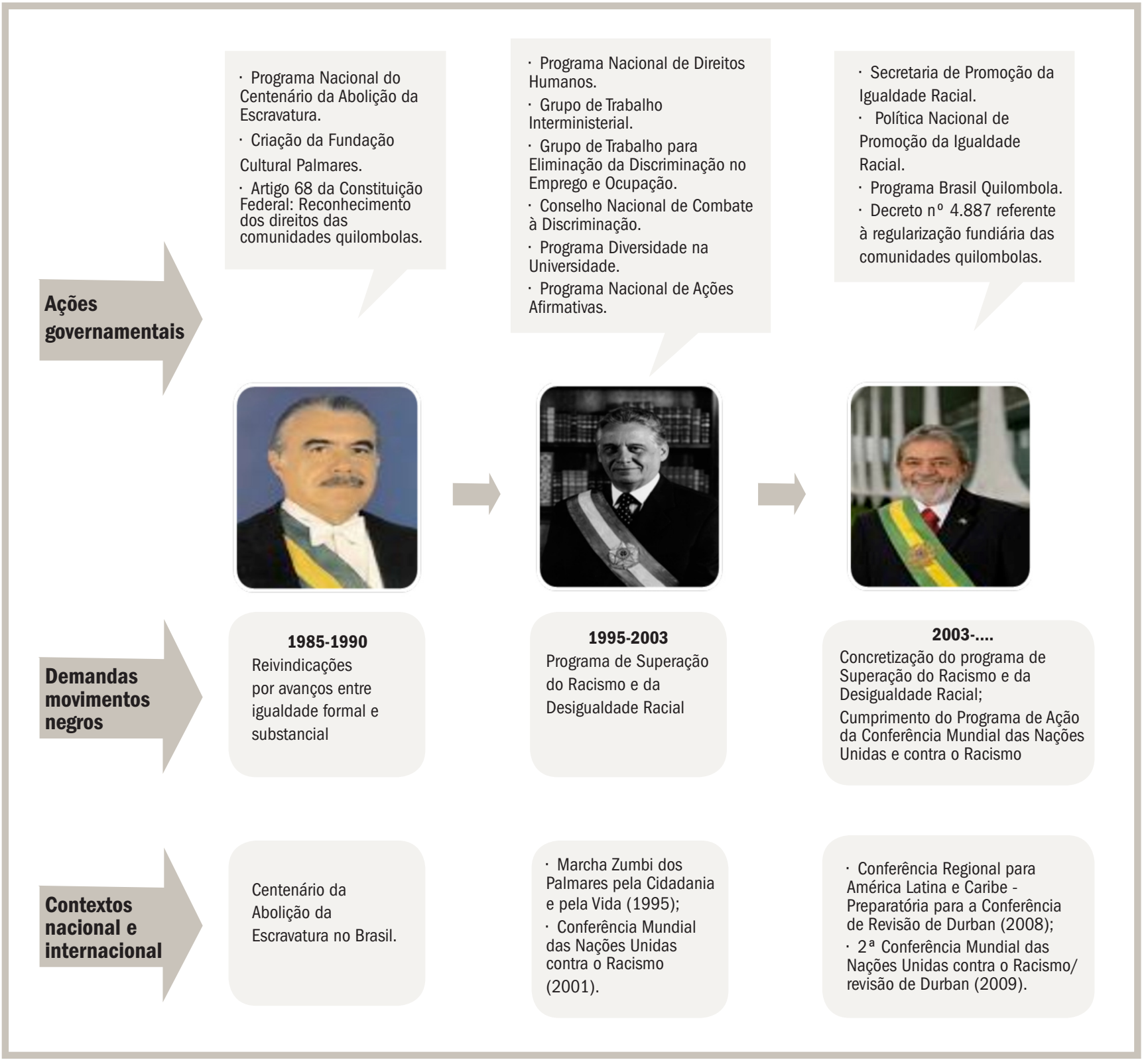


A construção do atual quadro de políticas de promoção da igualdade racial vem sendo delineada desde o final dos anos 1980. Nesse intervalo de tempo, os atores políticos em foco, movimentos negros e o Estado, interagiram num cenário feito de mobilizações, definições de pautas e estratégias políticas. Quando falo em movimentos negros, refiro-me às diversas gerações de militantes e organizações negras que compuseram um mosaico de bandeiras de luta e formas de mobilização e ação, mas mantendo o fio condutor da luta antirracista. Assim, interagiram nesse período organizações com reconhecimento regional e/ ou nacional, a começar por aquelas fundadas nos anos 1970, tais como: Instituto de Pesquisa das Culturas Negras (IPCN, Rio de Janeiro, 1975), Movimento Negro Unificado (MNU, São Paulo, 1978) e Centro de Cultura Negra do Maranhão (CCN, Maranhão, 1979).

Dos anos 1980 veio uma militância composta por entidades recentemente instituídas, tais como a União de Negros pela Igualdade (Unegro, Bahia, 1988) e as primeiras ONGs negras, destacando-se: Maria Mulher Organização de Mulheres Negras (Rio Grande do Sul, 1987), Geledés - Instituto da Mulher Negra (São Paulo, 1988) e o Centro de Articulação de Populações Marginalizadas (Ceap, São Paulo, 1989). A atuação conjunta desses militantes e organizações exigiu a construção de uma pauta comum, permeada pela heterogeneidade de temas representativos de cada entidade, da realidade social em que estava inserida, bem como da época vivida. Por conta disso, temas antigos como a violência policial contra a população negra - fator de contínua denúncia pelo MNU - foi evidenciado ao lado de novos temas trazidos, especialmente, pelas ONGs de mulheres negras, as quais colocaram em evidência o feminismo negro, por meio do debate sobre a participação das mulheres nas organizações negras e a defesa de políticas públicas com recorte de gênero e raça.

Por conta disso, avalio também como elemen- to de redefinições temáticas dos movimentos negros nos anos 1980 o lugar social de onde emergiram as novas organizações. Se nos anos 1970 muitos militantes vinham de entidades de classe e culturais, agora eles e elas vinham de segmentos religiosos, grupos de estudantes universitários e partidos políticos. Por exemplo, nessa linha, enquadram-se respectivamente os Agentes de Pastoral Negros (APNs, Igreja Católica, 1983), os grupos de religiosos de matriz afro-brasileira (Candomblé, Umbanda e Batuque); o Grupo Negro da PUC-SP (São Paulo, 1979-1983), o qual deu origem à Soweto Organização Negra (São Paulo, 1991); a secretaria de combate ao racismo do Partido dos Trabalhadores (PT, São Paulo, 1980); a secretaria nacional do movimento negro do Partido Democrático Trabalhista (PDT, Rio de janeiro/Rio Grande do Sul, 1980) e os Conselhos de Participação e Desenvolvimento da Comunidade Negra (órgãos consultivos de caráter municipal e estadual presentes em vários estados brasileiros).

Esse painel de temas e lugares de atuação militante contribuiu para a formatação de discursos e práticas políticas capazes de responder à articulação necessária com o poder executivo. Para que isso acontecesse, sem dúvida houve um exercício coletivo de acomodação e/ou superação de inúmeras questões internas. Assim deve ter ocorrido em relação às diferenças político-partidárias, às contradições entre a representatividade feminina e masculina ou ainda ao viés religioso defendido. Dessa construção política, consolidaram-se novas organizações, como a Coordenação Nacional das Entidades Negras (Conen, São Paulo, 1991), o Centro de Estudos das Relações de Trabalho e Desigualdades (Ceert, São Paulo, 1991), a Criola (Rio de Janeiro, 1992) e Educação e Cidadania de Afrodescendentes e Carentes (Educafro, Rio de Janeiro/São Paulo, 1995), as quais, juntamente com outras organizações anteriormente citadas - lembrando que os movimentos negros extrapo- 


\section{VERA RODRIGUES}

lam os limites deste texto -, foram a cara e a voz negra dos anos 1990.

Retornando ao final dos anos 1980, saliento no contexto nacional os eventos de promulgação da Constituição Cidadã e o centenário da Abolição da Escravatura. O conteúdo simbólico do centenário se assentava nas ideias de "liberdade" e "democracia racial", porém isso foi alvo de crítica por parte de organizações dos movimentos negros que repudiavam o tom celebrador do centenário, e reivindicavam medidas concretas de igualdade a partir da nova Constituição Federal:

Eu acho que em 1988 o movimento negro brasileiro deu a resposta adequada ao Estado brasileiro, às tentativas de manipular o sentido do centenário da abolição. Aquilo que a gente havia definido anos atrás como uma data de denúncia, acho que a gente fez isso cabalmente no contexto do centenário (Sueli Carneiro em entrevista concedida a PEREIRA, 2009, p. 252).

A resposta dos movimentos negros transpareceu, por exemplo, via mobilização na Marcha contra a Farsa da Abolição, realizada no Rio de Janeiro em maio de 1988. Além dessa mobilização visível, aconteceram outras articulações não tão visíveis, mas que impulsionaram ações em todo o país. Exemplo dessas articulações foi a presença de militantes nos núcleos de partidos políticos, sindicatos, bem como nas coordenadorias, programas e conselhos da população negra que começavam a ser criados nesse momento, nos âmbitos municipal, estadual e federal, e que imprimiram força às reivindicações. Esse diálogo tão próximo com o Estado não foi fácil nem aceitável para todos os envolvidos, já que para alguns significava a cooptação do militante pela máquina estatal, sendo essa apenas uma das questões delicadas e em jogo no momento.

A principal ação do governo em resposta à pressão militante foi a criação da Fundação Cultural Palmares (FCP), a qual nascia como a primeira instância responsável por formular e implantar políticas públicas para a população negra. Para alguns, isso representou um avanço na concretização de uma pauta política, porém, para outros, o caráter cultural da Fundação revelava o lugar em que, preferencialmente, a problemática racial era definida e tratada. Esse último entendimento se fez sentir quando se verificou que a Fundação não dispunha de poder legal, técnico e orçamentário para titular os territórios quilombolas uma das atribuições previstas inicialmente -, mas apenas o de emitir certidões de reconhecimento como comunidade quilombola. Apesar dos limites impostos à plena atuação da Fundação Palmares, não apenas na questão quilombola, a "visão de futuro" que consta em sua apresentação institucional é de "consolidar-se como instituição de referência nacional e internacional na formulação e execução de políticas públicas da cultura negra". A ênfase sobre "cultura negra" revela outro caminho possível de direcionamento que não é excludente aos anseios de participação, reconhecimento e visibilidade da população negra.

$\mathrm{Na}$ fase intermediária, governo Fernando Henrique Cardoso, o contexto em parte assemelhase ao anterior: uma data a celebrar (tricentenário da morte de Zumbi dos Palmares, 1995) e nova marcha oposicionista dos movimentos negros (Marcha Zumbi dos Palmares pela Cidadania e pela Vida, Brasília, 20 de novembro de 1995). A marcha até hoje é considerada um momento histórico para os militantes, já que exigiu o enfrentamento das fragilidades dos movimentos (apoio financeiro, organização interna, superação de antagonismos etc.), além de ampliar o horizonte das articulações com centrais sindicais, políticos de esquerda e outros atores que vieram a construir a agenda política.

Em relação às diferenças com o contexto político anterior, cabe atentar para o seguinte: primeiro, a marcha origina um documento intitulado Programa de Superação do Racismo e da Desigualdade, o qual foi um conjunto de reivindica- 
ções cujo ponto central era a ênfase nas políticas públicas para a população negra, conforme excertos a seguir:

- Inclusão do quesito cor nos sistemas de dados governamentais.

- Incentivos fiscais para empresas que adotassem políticas de promoção da igualdade racial em seus quadros de funcionários.

- Desenvolvimento de ações afirmativas no acesso à educação básica ao nível superior.

Dentre as ações governamentais desencadeadas, está a criação de um grupo de trabalho interministerial, composto por membros dos movimentos negros e do próprio governo. O GTI, como ficou conhecido, sinalizou em seus objetivos para o atendimento da demanda por políticas públicas.

- Elaborar, propor e promover políticas governamentais antidiscriminatórias e de consolidação da cidadania da população negra.

- Estimular e apoiar iniciativas públicas e privadas.

Obviamente, que isso não significou a efetivação plena das reivindicações, mas cimentou o caminho para a continuidade delas. Em segundo lugar, outro diferencial marcante no contexto dos anos 1990 foi a fala presidencial assumindo o racismo como um problema pertinente ao Brasil e mais ainda, segundo Santos b (2009, p. 13), o reconhecimento que "as históricas desigualdades raciais necessitariam de tratamento específico por parte do Estado".

No final do $2^{\circ}$ mandato, militância e governo, são influenciados pelo debate internacional trazido pela Conferência Internacional das Nações Unidas contra o Racismo, realizada em Durban/ África do Sul em 2001. As organizações negras promoveram encontros preparatórios, inclusive abrangendo outros países latino-americanos como exemplifica a Conferência de Santiago (2000). Nesses espaços de interlocução construíram-se consensos relacionados às ações afirmati- vas e eixos temáticos levados para Durban. É nesse contexto que se entrelaçam o local e o global da pauta dos movimentos negros, bem como o Brasil torna-se signatário de acordos e convenções internacionais na área de direitos humanos e cidadania.

No governo seguinte, mais precisamente no Dia Internacional pela Eliminação da Discriminação Racial, 21 de março de 2003, foi criada a Secretaria Especial de Políticas de Promoção da Igualdade Racial (Seppir), a qual pretende, entre os seus objetivos: "Acompanhar e coordenar políticas de diferentes ministérios e outros órgãos do governo brasileiro para a promoção da igualdade racial". Apesar do status ministerial que a Seppir recebeu, houve limitações e impasses no atendimento aos objetivos propostos. Nesse contexto foi cobrado o cumprimento do Programa de Superação do Racismo e Desigualdade Racial e também as propostas de políticas públicas aprovadas na Conferência de Durban.

Esse processo desencadeia novas ações governamentais, dentre elas o foco deste ensaio, o Programa Brasil Quilombola (PBQ). Em 2004, logo após a criação da Seppir, o PBQ, ao pautar-se nas garantias constitucionais de direitos às comunidades quilombolas, enfrenta um dos pontos nevrálgicos da formação social brasileira: o acesso à terra e a problemática racial que agora se entrelaçam na regularização fundiária, e políticas de promoção da igualdade racial para as comunidades quilombolas brasileiras.

\section{PANORAMA DO PROGRAMA BRASIL QUILOMBOLA NO PERÍODO 2004-2009}

O Programa Brasil Quilombola é um conjunto de medidas descentralizadas entre instituições governamentais nos âmbitos federal, estadual, municipal e organizações da sociedade civil, co- 
ordenadas pela Seppir por meio da Subsecretaria de Políticas para Comunidades Tradicionais. Tais medidas foram estruturadas em quatro eixos: 1) Regularização Fundiária; 2) Infraestrutura e Serviços; 3) Desenvolvimento Econômico e Social e 4) Controle e Participação Social. Por uma questão de centralidade na regularização fundiária, opto por não trazer uma visão do conjunto desses eixos. ${ }^{3}$ Assim o faço por entender que o processo de regularização fundiária comporta a maior parte dos interesses e conflitos em jogo, explicitando assim a problemática de uma política pública específica e de caráter redistributivo.

A regularização fundiária compreende uma série de etapas administrativas, que começam com a abertura de processo junto ao Incra, seguida da elaboração do Relatório Técnico de Identificação e Delimitação (RTID, composto por informações socioeconômicas, históricas, antropológicas, geográficas etc.), portaria de reconhecimento territorial publicada no Diário Oficial (União e Estado) e, após, a emissão dos títulos. Todo esse processo é atravessado por normas legais referentes a prazos para interposição de recursos judiciais, publicações de editais, bem como procedimentos de desapropriação e indenização de proprietários, quando for o caso. Além do previsível, também ocorrem mandados de segurança, impugnações ao RTID, ações judiciais contrárias à legislação pertinente à regularização fundiária quilombola, entre outras ações de cunho político e midiático que trazem à tona interesses e tensões múltiplas.

O grau de importância da titulação territorial pode ser avaliado tanto pelos entraves à sua efetivação quanto pela ótica do seu significado para as comunidades quilombolas. O território é fundamental para a reprodução física, social e cultural das comunidades. Nesse sentido, vai além da dimensão da terra como espaço físico e geográfico, mas consiste na base mantenedora da historicidade, coesão e existência das gerações atuais e futuras. As maiores cobranças em termos de gestão eficiente dos recursos orçamentários, representação pública dos interesses das comunidades e consolidação da política fundiária concentramse no Instituto de Colonização e Reforma Agrária (Incra, responsável pelo processo de titulação), na FCP (órgão emissor da certidão de autorreconhecimento quilombola) e na Seppir (órgão de coordenação da política). O gráfico da Figura 2, abaixo, expõe o andamento da regularização fundiária no período de 2004-2009:
Figura 2

Fundação Cultural

Palmares: certidões e títulos emitidos Incra - DFQ 2010

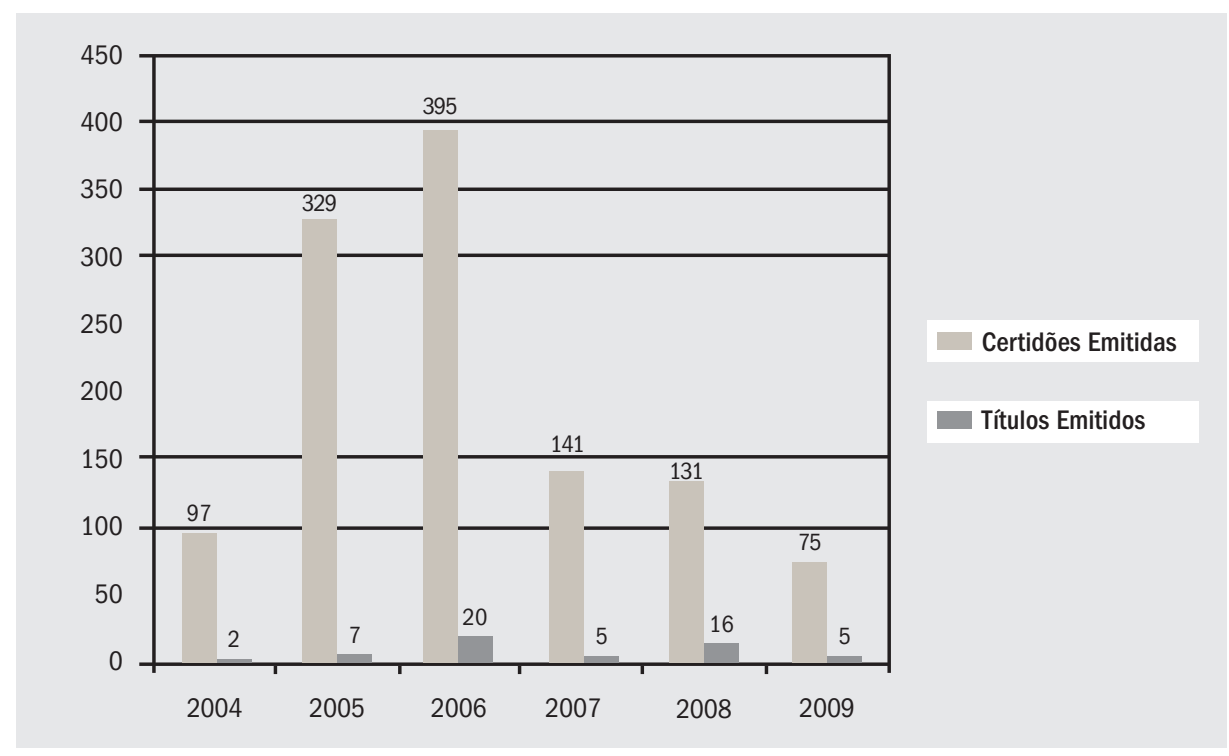


O gráfico contrasta a partir do período de criação do PBQ e também quando passa da competência da FCP para o Incra a regularização dos territórios quilombolas, o número de certidões de autoidentificação das comunidades quilombolas emitidas pela FCP com os títulos de posse emitidos pelo Incra e/ou órgãos estaduais parceiros. $\mathrm{O}$ número maior de certificações que titulações evidencia as fases do intrincado processo fundiário. Na fase inicial, junto à FCP, prevalece a articulação política das comunidades e movimentos negros para dar os primeiros passos rumo ao reconhecimento. Porém, a chegada ao ponto final dessa caminhada significa cruzar a zona burocrática, técnica e política que se impõe à titulação. Até agora, poucas comunidades têm cruzado essa zona. Segundo a última atualização do Incra, realizada em outubro de 2010, foram emitidos desde 1995, ${ }^{4}$ 113 títulos que regularizaram 971.297,6881 hectares, em benefício de 104 territórios, 183 comunidades e 11.506 famílias quilombolas.

Não quero resvalar para o tom de denúncia ou intervenção já criticado por Arruti c (2009), mas é preciso dizer também que, se os números impressionam, a realidade não faz o mesmo. Ainda segundo o mesmo autor, estimava-se em 2009 a existência de 3.900 comunidades em todo o Brasil, sendo que há em andamento no Incra 996 processos abertos. Portanto, os dados oficiais representam uma amostra do universo total, considerando que, pela própria dinâmica de reconhecimentos e demandas, trata-se de um fenômeno em expansão.

Cabe ressaltar que não se trata de atestar ineficiência deste ou daquele órgão governamental, mas demonstrar onde está o gargalo da questão. Por que o número de titulações não corresponde ao mesmo número de certificações? Por que, coincidentemente, no ano eleitoral de 2006, certificações e titulações atingem os números mais elevados do período? Para responder à primeira questão é preciso refletir sobre os significados de "certificar" uma comunidade quilombola e "titular" o território dessa comunidade. Na certificação, dá-se apenas o reconhecimento oficial de uma situação preexistente, de um território formalmente ocupado, ou seja, altera-se o status social do grupo, sem promover a sustentabilidade desse status.

Em outras palavras, não basta ser uma comunidade quilombola, mas é preciso garantir a sua existência como tal. Esse é o passo seguinte que a titulação deveria contemplar em toda a sua extensão e potencial político. Porém, isso significa fragilizar ou romper com lógicas históricas de apropriação da terra, leia-se concentração e propriedade, o que em última instância também significa afetar as linhas demarcatórias de raça/cor que construíram o lugar social da população negra brasileira.

Esse é um efeito cascata, não perceptível a médio prazo, mas que a longo prazo pode implicar mudanças sociais efetivas. Por enquanto, entre a certificação e a titulação há uma correlação de forças que se sobrepõe aos interesses quilombolas. Nesse sentido, talvez só a crescente e articulada mobilização política, como a ocorrida em 2006 nas "brechas" de uma pressão/negociação em contexto favorável, possa alterar ou equilibrar essa balança.

As tentativas de respostas para essas e outras discrepâncias nos conduzem a uma análise que permite pensar na agência política dos atores, nas redes sociais constituídas e no poder de negociação. Sendo assim, por meio do diagrama da Figura 3, abaixo, retomo os modelos teóricos de arenas sociais e múltiplos fluxos para explicar a dinâmica nacional do Programa Brasil Quilombola e, posteriormente o caso do estado de São Paulo. 


\section{Figura 3 - Modelos teóricos de arena sociais na dinâmica do Programa Brasil Quilombola}

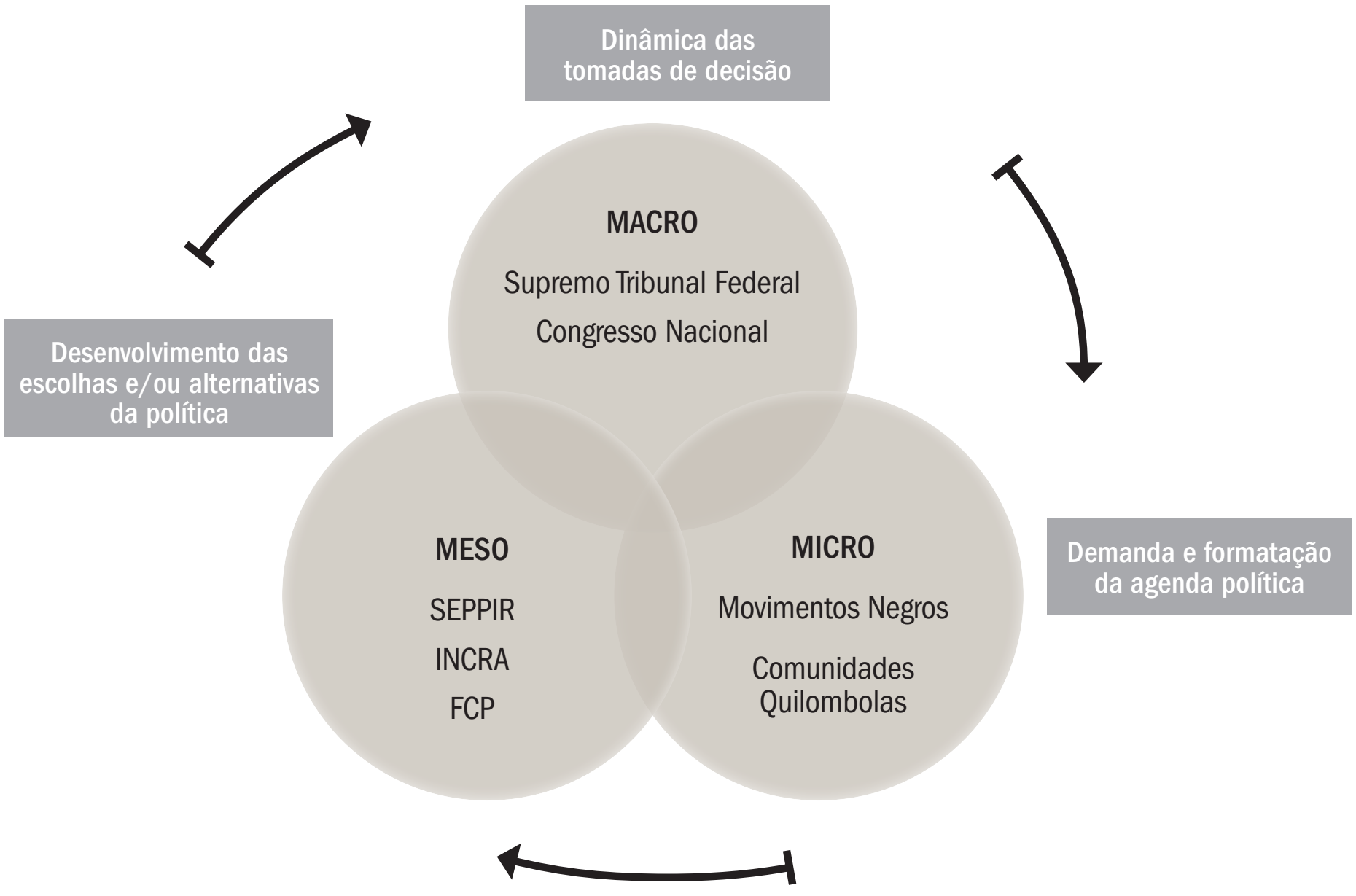

Partindo da interconexão entre arenas sociais, as quais expressam o conjunto de relações estabelecidas entre os atores, bem como os níveis espaciais - esferas micro, meso e macro - em que ocorrem (CARDOSO DE OLIVEIRA, 1998, p. 175), abordo alguns pontos para análise. Inicialmente, numa relação face a face, movimentos negros e comunidades quilombolas figuram como os empreendedores da política pública, segundo Souza (2006), que via seu agenciamento político e atuação em rede transformar demandas em problemáticas que chamam a atenção dos policy makers do governo.

No âmbito governamental, o qual pode ser aqui subdividido nas esferas meso e macro, no começo há uma articulação em torno da formulação da política pública, considerando alternativas e escolhas que incidem não só sobre seu formato final, bem como sua implementação. Destaco aqui dois fatos exemplares sob essa ótica: a Instrução Normativa $n^{\circ}$ 49/2008 do Incra e as negociações em torno do Estatuto da Igualdade Racial. No primeiro caso, foram introduzidas mudanças no processo de regularização que foram consideradas pelas comunidades quilombolas, movimentos negros e entidades ligadas à questão como entraves burocráticos às titulações: a) autoidentificação quilombola condicionada à emissão de 
certidão da FCP; b) novos quesitos obrigatórios para a identificação do território; c) restrições aos convênios com universidades e contratações de antropólogos para a confecção dos estudos antropológicos.

Para uma ideia geral da tensão ocasionada, essa instrução normativa chegou a ser parcialmente revogada pela presidência do Incra, mas voltou-se atrás nessa decisão. Também surgiram documentos públicos de protesto, tais como a "Carta de Repúdio aos Ataques contra o Povo Quilombola”, da Coordenação Nacional de Articulação das Comunidades Negras Rurais Quilombolas (Conaq); o "Manifesto Quilombola", da Federação das Comunidades Quilombolas do Rio Grande do Sul (FACQ/RS); a carta "Pela Garantia dos Direitos das Comunidades Remanescentes de Quilombos", elaborada por organizações e entidades diversas; e a "Carta de Porto Seguro", da Associação Brasileira de Antropologia (ABA).

O segundo caso foi a retirada do capítulo relativo aos direitos territoriais quilombolas, o qual fazia parte do projeto de lei "Estatuto da Igualdade Racial", que prevê políticas públicas para a superação da desigualdade racial. O capítulo teria um conteúdo considerado mais rígido e eficaz, pois consolidaria o marco legal existente e, segundo interpretações, abriria caminho para transformar uma política pública de governo em política pública de Estado. Para os opositores dessa interpre- tação, tratava-se de dispositivo inconstitucional, pois o artigo 68 da Constituição Federal, que trata do tema, seria autoaplicável, não necessitando de novo referendo legal.

O contexto de retirada do capítulo fez parte de uma negociação envolvendo Seppir, FCP e congressistas do partido Democratas (DEM), os quais condicionavam seu apoio à aprovação do estatuto, em trâmite há dez anos no Congresso, à retirada do item quilombola, bem como das cotas para negros nas universidades, nos meios de comunicação social e incentivos fiscais para a contratação de trabalhadores negros. O Estatuto foi aprovado com essas modificações. Não é preciso dizer que, além de protestos, essa negociação evidencia as escolhas e alternativas possíveis no cenário conflituoso de interesses que moldam essa política pública. Isso prossegue nas tomadas de decisão, ainda em suspenso, que o Supremo Tribunal Federal fará sobre a Ação Direta de Inconstitucionalidade (ADIn $n^{\circ}$ 3.229) ajuizada pelo partido DEM contra o Decreto n. 4.887/2003, que diz respeito à regularização fundiária quilombola.

Toda essa dinâmica possui uma dimensão cíclica e de interconexão, já que não é algo estanque, mas que contém elementos de mobilização, articulação, demandas e respostas dos atores envolvidos. O mesmo se aplica, para uma análise de caso, à situação quilombola no estado de São Paulo:

Quadro 1 - Títulos expedidos Incra - DFQ 26/08/2010

\begin{tabular}{|c|c|c|c|c|c|c|c|c|}
\hline \multicolumn{9}{|c|}{ TÍTULOS EXPEDIDOS ÀS COMUNIDADES QUILOMBOLAS } \\
\hline Terra quilombola & Comunidade(s) & $\begin{array}{c}\mathrm{N}^{\circ} \text { de } \\
\text { comunidades }\end{array}$ & $\begin{array}{l}N^{\circ} \text { de } \\
\text { famílias }\end{array}$ & Área (ha) & Município & UF & $\begin{array}{l}\text { Órgão } \\
\text { expedidor }\end{array}$ & Data \\
\hline $\begin{array}{l}\text { Ivaporunduva * } \\
\text { (10 título) }\end{array}$ & Ivaporunduva & 1 & 82 & $3.158,1100$ & Eldorado & SP & FCP & $14 / 07 / 00$ \\
\hline $\begin{array}{l}\text { Porto dos Pilões } \\
\qquad *\end{array}$ & Porto dos Pilões & 1 & 51 & $5.908,6824$ & Iporanga & SP & Itesp & $15 / 01 / 01$ \\
\hline São Pedro ** & São Pedro & 1 & 39 & $4.558,1986$ & $\begin{array}{l}\text { Eldorado e } \\
\text { Iporanga }\end{array}$ & SP & Itesp & $15 / 01 / 01$ \\
\hline
\end{tabular}




\begin{tabular}{|c|c|c|c|c|c|c|c|c|}
\hline \multicolumn{9}{|c|}{ TÍTULOS EXPEDIDOS ÀS COMUNIDADES QUILOMBOLAS } \\
\hline Terra quilombola & Comunidade(s) & $\begin{array}{c}\mathrm{N}^{0} \text { de } \\
\text { comunidades }\end{array}$ & $\begin{array}{l}N^{\circ} \text { de } \\
\text { famílias }\end{array}$ & Área (ha) & Município & UF & $\begin{array}{l}\text { Órgão } \\
\text { expedidor }\end{array}$ & Data \\
\hline Maria Rosa ** & Maria Rosa & 1 & 20 & $3.375,6582$ & Iporanga & SP & Itesp & $16 / 01 / 01$ \\
\hline $\begin{array}{l}\text { Ivaporunduva ** } \\
\left(2^{\circ} \text { título }\right)\end{array}$ & Ivaporunduva & - & - & 672,2844 & Eldorado & SP & Itesp & 20/03/03 \\
\hline Pedro Cubas ** & Pedro Cubas & 1 & 40 & $2.443,7210$ & Eldorado & SP & Itesp & 20/03/03 \\
\hline Galvão & Galvão & 1 & 32 & $1.869,5711$ & $\begin{array}{l}\text { Eldorado e } \\
\text { Iporanga }\end{array}$ & SP & Itesp & $18 / 01 / 07$ \\
\hline TOTAIS & - & 6 & 264 & $21.986,2257$ & - & - & - & - \\
\hline
\end{tabular}

Observações:

* Territórios titulados pela FCP sem a retirada ou indenização dos ocupantes não quilombolas (proprietários e/ou posseiros).

** Territórios cujos títulos contêm cláusulas suspensivas.

A Região Sudeste possui, segundo última atualização de dados Incra, de outubro de 2010, 210 processos de regularização fundiária de quilombos abertos, sendo que 47 destes se referem ao estado de São Paulo entre os anos de 2004 e 2008. Em termos de processos finalizados, ou seja, titulados, temos seis comunidades dentre aquelas 44 que já obtiveram a certidão emitida pela FCP. As observações constantes no Quadro 1, acima, indicam que as titulações enfrentam impedimentos legais para sua efetiva conclusão, além de possível comprometimento na implementação da política pública.

Se assim for, o comprometimento espelha o quadro geral da arena política e jurídica em torno do Programa Brasil Quilombola ou da efetivação de direitos territoriais quilombolas, em termos amplos. Em São Paulo, um momento que ilustrou esse ponto de vista foi por ocasião do lançamento da Federação Quilombola do estado. Em 2009, na véspera do dia da Consciência Negra, esse evento reuniu advogados, militantes, representantes do Incra, Itesp e quilombolas das comunidades de Agudos, Caçandoquinha, Cafundó, Do Carmo, Porcinos e Porto dos Pilões.

A Federação surgiu da articulação entre lide- ranças quilombolas e militantes negros locais, os quais já atuavam, por exemplo, no atendimento jurídico de demandas quilombolas. Esse processo resultou na criação da Federação durante o VI Encontro de Comunidades Quilombolas realizado no quilombo de Caçandoquinha (Ubatuba/SP) no mês de agosto de 2009. Nessa ocasião, lideranças quilombolas e membros do CNAB - Congresso Nacional Afro-Brasileiro, Instituto Luiz Gama e Frente Parlamentar em Defesa das Comunidades Quilombolas reiteraram apoio às comunidades. Por ocasião do lançamento, em novembro, os quilombolas expuseram os problemas que mais demandavam solução imediata: andamento nos processos de regularização; intensificação do diálogo com o poder público; cumprimento de acordos nas áreas de educação, saúde e habitação e medidas legais contra atos de violência sofridos pelas comunidades.

O ponto crucial das falas girou em torno da necessidade de constituir a Federação como medida de fortalecimento dos interesses coletivos, além de cumprir o papel de pressionar o poder público em prol das demandas quilombolas. Interessante observar que algumas dessas falas já se posicionavam enquanto movimento social, o movimento 
quilombola. A construção de uma relativa autonomia orientada pela defesa de direitos comuns e visando investir na coesão do grupo apontou para novas lógicas de ação frente às respostas de suas demandas. Porém, isso não significava dispensar aliados, especialmente na área jurídica, onde alguns já identificam uma arena privilegiada para assegurar direitos.

Ainda que houvesse o incômodo da cobrança de soluções dirigidas àqueles que ali representavam o poder público (Incra e Itesp), as manifestações destes aliaram-se na perspectiva de apoio às intenções dos membros da Federação Quilombola de buscar solidificar suas ações, além de manter uma postura questionadora da política pública. Os militantes de diversos movimentos ali presentes (Instituto Luiz Gama, Afropress, Sindicato dos Advogados de São Paulo, UneAfro Brasil e outros) mantiveram a postura de aliança à causa quilombola. No entanto, ainda é cedo para analisar os ganhos e perdas dessa caminhada frente aos obstáculos de fazer cumprir uma política pública que traz no seu cerne a complexidade das relações raciais e do acesso à terra. Uma boa interpretação dessa problemática ficou no registro da fala do presidente da Federação Quilombola, sr. Luiz Mariano dos Santos, oriundo do quilombo do Carmo: "Eles não se conforma de nego fica na terra!".

\section{CONSIDERAÇÕES FINAIS}

Ao longo deste ensaio, procurei abarcar as dimensões teóricas e empíricas implícitas às políticas públicas de promoção da igualdade racial para quilombos. Agora, ao término deste texto, tenho a noção da necessária continuidade desta e outras reflexões motivadas pelo desafio de compreensão das relações etnorraciais no cenário brasileiro e latino-americano. Nas interconexões teóricas de arenas e esferas sociais, nos contextos local/global, o viés analítico transnacional surge como uma proposta dialógica entre realidades próximas. Isso vai ao encontro de uma tendência, especialmente nos estudos sobre relações etnorraciais, a tratar da experiência brasileira limitada aos parâmetros contrastivos, quando não fontes originais e exclusivas, dos modelos de casos dos Estados Unidos da América ou da África do Sul.

Isso não significa deixar de atentar para um diálogo já preexistente entre movimentos negros e poder público com agências internacionais - ONU, Unesco, Comissão Interamericana de Direitos Humanos etc. -, legislação e acordos internacionais -Convenção 169 da Organização Internacional do Trabalho (OIT), Pacto Internacional de Direitos Econômicos, Sociais e Culturais (Pidesc) etc. -, conforme apresentado em relação à Conferência de Durban, por exemplo. Esses elementos compõem e enriquecem o quadro sociopolítico do Brasil (1988), Colômbia (1991) e Equador (1998) países que reconhecem nas suas constituições direitos de comunidades negras. Entre esses países, também há em comum o desenvolvimento de políticas públicas direcionadas para esse segmento populacional.

Tais políticas recebem terminologias próprias, adequadas tanto ao contexto nacional quanto aos princípios que as embasam, por isso podem ser de "promoção da igualdade racial", "afro-reparaciones" ou simplesmente "ações afirmativas". No Brasil, o Programa Brasil Quilombola enquadrase como uma política que, nos seus eixos de atuação, principalmente a regularização fundiária, expõe toda a complexidade da articulação entre novos sujeitos de direitos, o poder público e movimento social. No plano teórico, remexe com o "esqueleto no armário" que representam os conceitos de "raça", "desigualdades", "equidade", que tanto já foram a base de estudos temáticos e, mais recentemente, servem aos debates sobre as consequências sociais aplicadas à sociedade de seus 


\section{VERA RODRIGUES}

usos e desusos.

Por conta disso, a inter-relação entre política pública e equidade pode vir a ser a transição entre política de governo e política de Estado; entre desigualdades e justiça social. Espera-se que, num futuro próximo, novas análises venham a contemplar uma nova realidade brasileira.

\section{NOTAS}

${ }^{1}$ Por população negra compreende-se a soma classificatória do IBGE para pretos e pardos.

${ }^{2} \mathrm{Na}$ adoção da terminologia "movimentos negros" em oposição a "movimento negro" no singular, me filio à interpretação de autores como PEREIRAb (2006) e SANTOSb (2009), que realçam a dimensão plural e plástica desse movimento social que contempla organizações com diferentes pautas, escopos, objetivos e formas de intervenção social.

${ }^{3}$ Para uma visão conjuntural dos eixos programáticos do Programa Brasil Quilombola, ver ARRUTIc (2009).

${ }^{4}$ No período que antecede ao Decreto n. 4.887/03, que delega ao Incra a competência para o processo administrativo da regularização fundiária, ocorreram titulações territoriais emitidas por órgãos estaduais em parceria com o Incra/Ministério do Desenvolvimento Agrário. Assim procedem, principalmente, o Instituto de Terras do Pará (Iterpa), o Instituto de Terras do Maranhão (Iterma), o Instituto de Terras de São Paulo (Itesp) e a FCP.

\section{REFERÊNCIAS}

ARRUTI, J. M. Quilombos. In: Raça: novas perspectivas antropológicas. PINHO, O.; SANSONE, L. (Orgs.) 2. ed. Salvador: ABA; Edufba, 2008. p. 315-350.

Políticas públicas para quilombos: terra, saúde e educação. In: Caminhos Convergentes: Estado e sociedade na superação das desigualdades raciais no Brasil. PAULA, M.; HERINGER, R. (Orgs.) Rio de Janeiro: Fundação Heinrich Boll/Actionaid, 2009. p. $75-110$.

BACELAR, T. As políticas públicas no Brasil: heranças, tendências e desafios. Disponível em: <http/www4.fct.unesp.br/.../textol_politicas_publicas_n_br_taniabacelar.pdf>. Acesso em 24 fev. 2010.

CAPELLA, A. C. N. Perspectivas teóricas sobre o processo de formulação de políticas públicas. In: HOCHMAN, G. et al. (Orgs.) Políticas públicas no Brasil. Rio de Janeiro: Fiocruz, 2007. cap. 3 , p. $87-122$.

CARDOSO DE OLIVEIRA, R. O trabalho do antropólogo. São Paulo:
Unesp/Paralelo 15, 1998.

DAGNINO, E. Os movimentos sociais e a emergência de uma nova noção de cidadania. In: Anos 90: política e sociedade no Brasil. DAGNINO, E. (Org.). São Paulo: Brasiliense, 1994. p. 103115.

JACCOUD, L. O combate ao racismo e à desigualdade: o desafio das políticas públicas de promoção da igualdade racial. In: THEODORO, M. et al. (Org.) As políticas públicas e a desigualdade racial no Brasil 120 anos após a Abolição. 2. ed. Brasília: Ipea, 2008. p. 135-170.

LIMA, A. C. S.; CASTRO, J. P. M. E. Política(s) pública(s). In: Raça: novas perspectivas antropológicas. PINHO, O.; SANSONE, L. (Orgs.) 2. ed. Salvador: ABA; Edufba, 2008. p. 351-392.

ORGANIZAÇÃO do Instituto Amma Psique e Negritude e Articulação Nacional de Combate ao Racismo Institucional. Articulação para o combate ao racismo institucional. São Paulo: Instituto Amma; ANCRI, 2006.

PEREIRA, A. M. Para além do racismo e antirracismo: a produção da cultura de uma cultura de consciência negra na sociedade brasileira. Tese de Doutorado em Ciências Sociais no Programa de Pós-graduação em Ciências Sociais, Universidade do Estado do Rio de Janeiro, Rio de Janeiro, 2006.

RIBEIRO, M. As políticas de igualdade racial no Brasil. Série Análises e Propostas no 35. São Paulo: Fundação Friedrich Ebert Stiftung, 2009.

SANTOS, M. Ser negro no Brasil hoje: ética enviesada da sociedade branca desvia enfrentamento do problema negro. 2000. Disponível em: <http://www.ige.unicamp.br/ lmelgaco/santos.htm>. Acesso em 26 fev. 2010.

SANTOS, M. A. O. Política negra e democracia no Brasil contemporâneo: reflexões sobre os movimentos negros. In: Caminhos convergentes: Estado e sociedade na superação das desigualdades raciais no Brasil. PAULA, M.; HERINGER, R. (Orgs.) Rio de Janeiro: Fundação Heinrich Boll; ActionAid, 2009. p. 227-258.

SILVA P. L. B.; MELO, M. A. B. O processo de implementação de políticas públicas no Brasil: características e determinantes da avaliação de programas e projetos. Campinas: Unicamp/Núcleo de Estudos em Políticas Públicas, Caderno n. 48, 2000. Disponível em: <http://www.nepp.unicamp.br/index.php?p=42>. Acesso em 07 fev. 2010.

SILVÉRIO, W. R. Evolução e contexto atual das políticas públicas no Brasil: educação, desigualdade e reconhecimento. In: Caminhos convergentes: Estado e sociedade na superação das desigualdades raciais no Brasil. PAULA, M.; HERINGER, R. (Orgs.) Rio de Janeiro: Fundação Heinrich Boll; ActionAid, 2009. p. 13-38.

SOUZA, Ca. Políticas públicas: uma revisão da literatura. Sociologias, Porto Alegre, ano 8, n. 16, , p. 20-45, 2006. 